\title{
Descobrindo novas palavras no fluxo da fala: o impacto da prosódia na aquisição lexical
}

Maria Cristina Name (UFJF)

Recebido 15, jan. 2011/Aprovado, 7 mar. 2011

\section{Resumo}

Discute-se o papel da informação prosódica na aquisição lexical por crianças adquirindo o português do Brasil, tendo por foco elementos da categoria lexical ADJ(etivo). Assume-se que a fala se organiza em constituintes prosódicos hierarquicamente dispostos, parcialmente sensiveis à estrutura sintática, e defende-se que adultos e crianças usam pistas prosódicas para o reconhecimento da posição do adjetivo no DP (Experimento 1), identificam pseudopalavras como novos adjetivos (Experimento 2) e atribuem valor subjetivo ao realce prosódico do adjetivo anteposto a $N(E x-$ perimento 3). Discutem-se os resultados obtidos à luz de modelos de processamento comprometidos com a aquisição de linguagem.

Palavras-chave: aquisição lexical, prosódia, adjetivo, bootstrapping fonológico, DP. 


\section{Introdução}

Compreender o rápido processo de aquisição de uma língua pela criança é, ainda, um desafio para as ciências. No que se refere especificamente à aquisição do léxico, busca-se entender como o bebê/a criança segmenta o fluxo da fala em elementos menores e os extrai, para que possa então mapear essas unidades linguísticas com entidades semânticas ligadas a referentes do mundo (FRIEDERICI \& THIERRY, 2008; SNEDEKER \& GLEITMAN, 2004). Para dar conta das etapas iniciais do processo, anteriores à apreensão de significado, o modelo de Bootstrapping Fonológico (MORGAN \& DEMUTH, 1996; CHRISTOPHE ET AL., 1997) defende que habilidades perceptuais permitem ao bebê processar informação fonológica dos enunciados, levando à identificação de unidades sintáticas. Tais habilidades também seriam usadas no processamento de falantes que já adquiriram uma lingual (ou mais). Para esse modelo, o envelope prosódico da fala, sensível à sua estrutura sintática (cf. NESPOR \& VOGEL, 1986; SELKIRK, 1984), tem um papel fundamental, delimitando unidades linguísticas menores, facilitando sua segmentação e sinalizando, dessa forma, elementos distintos que poderiam ser adquiridos (no processo de aquisição de uma língua) ou reconhecidos (no processamento adulto) como membros de diferentes categorias lexicais e relacionados a conteúdo semântico.

Neste artigo, ilustraremos o papel da informação prosódica na aquisição de vocabulário por crianças adquirindo o português do Brasil (doravante, PB), focalizando elementos da categoria lexical ADJ(etivo). A partir da análise acústica da fala dirigida à criança, mostraremos que o envelope prosódico de sintagmas em que nomes e adjetivos se inserem se distingue em função da posição desses últimos em relação aos primeiros, permitindo que adultos reconheçam a posição de tais itens a partir da prosódia do DP. Em seguida, apresentaremos resultados de atividades experimentais sugerindo que crianças de três anos são guiadas por informação de natureza prosódica para identificar pseudopalavras como adjetivos e que tal informação também é usada por crianças mais velhas, de seis anos, sinalizando a mudança da ordem canônica do adjetivo em relação ao nome e delimitando o tipo de informação veiculada pelo adjetivo antesposto - qualificadora, subjetiva e não classificadora, objetiva.

\section{Algumas considerações sobre prosódia e aquisição de adjetivos}

A pesquisa experimental em aquisição da linguagem, nas últimas décadas, apresenta evidência de sensibilidade a propriedades prosódicas do estímulo linguístico que são usadas precocemente pelo bebê nas etapas iniciais da aquisição lexical (JUSCZYK, CUTLER, \& REDANZ, 1993; TURK, JUSCZYK, \& 
GERKEN, 1995). Bebês adquirindo inglês ou alemão começam a segmentar palavras no fluxo contínuo da fala a partir dos seis meses de idade (JUSCZYK \& ASLIN, 1995 para o inglês; HÖHLE \& WEISSENBORN, 2003 para o alemão). O início desse processo parece se dar um pouco mais tarde para bebês expostos ao holandês (HOUSTON ET AL., 2000; KUIJPERS ET AL., 1998 apud NAZZI ET AL., 2006) ou ao francês (NAZZI ET AL., 2006).

Pistas relativas a fronteiras de constituintes prosódicos são particularmente robustas, facilitando a segmentação lexical. Christophe e colaboradores (2003) observaram que bebês de 13 meses habituados a extrair determinada palavra alvo eram mais eficientes na tarefa quando essa palavra constituía de fato uma palavra (ex.: paper) do que em sentenças nas quais a palavra se posicionava em fronteira fonológica (ex.: pay performs), o que sugere o uso de fronteiras de sintagma fonológico na extração de palavras por bebês. Tais propriedades podem ser fontes privilegiadas de informação sintática, pois ainda que não haja isomorfia total entre a estrutura prosódica e a estrutura sintática (NESPOR \& VOGEL, 1986), fronteiras de alguns constituintes prosódicos podem delimitar estruturas sintáticas e lexicais.

A Fonologia Prosódica de Nespor e Vogel (1986) estabelece que a fala se organiza em níveis prosódicos hierarquicamente dispostos, com um constituinte se formando a partir do(s) constituinte(s) de nível imediatamente mais baixo em um total de sete domínios. O menor constituinte é a sílaba e o maior, o enunciado fonológico. Assumindo-se que a criança penetra na sintaxe de sua língua a partir da interface fonética/fonológica (cf. Modelo de Bootstrapping Fonológico: MORGAN \& DEMUTH, 1996; CHRISTOPHE ET AL., 1997), consideramos que propriedades da fala que sinalizam a estrutura sintática subjacente podem ser facilitadoras da identificação dos elementos lexicais. Além disso, consideramos também que especificidades do input ao qual a criança tem acesso - especificamente a fala dirigida à criança (FDC) - podem mediar esse processo, embora não constituam elementos essenciais para o desencadeamento da aquisição de uma língua.

Escolhemos tratar do aspecto prosódico na aquisição de adjetivos pelas seguintes razões: (a) de modo geral, as pesquisas relativas à identificação de adjetivos (e nomes) por crianças em processo de aquisição de primeira língua costumam focalizar processos semânticos e morfossintáticos (para revisão, ver WAXMAN, 2004), deixando de lado etapas anteriores de segmentação e identificação desses itens no enunciado linguístico. Como a maioria dos estudos é conduzida em inglês, cuja ordem dos elementos no sintagma determinante (DP) é rígida (Det-Adj-N), o problema de reconhecimento lexical parece ser menos complexo para a criança; (b) a relativa flutuação do adjetivo face ao nome no português poderia dificultar sua identificação, necessitando 
de informação semântica robusta, a menos que outra fonte de informação esteja disponível para a criança.

No português, o adjetivo aparece antes ou depois de N, com preferência pela posposição, podendo haver implicações semânticas na escolha (adjetivo anteposto tendo valor mais subjetivo, ligado à intenção do falante). A questão é se essas diferentes configurações sintáticas têm repercussões na estrutura prosódica do DP complexo, de modo que pudessem ser exploradas pelo bebê na segmentação desses elementos e posterior reconhecimento e atribuição de traços categoriais como N e ADJ. Para investigar esse ponto, analisaremos acusticamente DPs com adjetivos antepostos e pospostos presentes na fala dirigida à criança brasileira.

\section{Propriedades acústicas do DP em função da posição do adjetivo na FDC}

Matsuoka e Name (2011) analisaram os parâmetros de duração, intensidade e pitch de nomes e adjetivos em DPs seguindo tanto a ordem canônica quanto a não canônica do português (por meio do PRAAT: BOWERSMA \& WEENINK, 2001). Os dados foram obtidos de gravações de contação de história para a criança. Era pedido ao adulto (mãe ou professora) que inventasse uma historia a partir das imagens de um livro, sendo que algumas gravuras apresentavam pequenas passagens, textos cuja inserção na historia era obrigatoria. Foi usado esse artifício para garantir a produção de DPs pelos diferentes contadores de historia. Também foram apresentadas imagens com frases distratoras, de modo que os participantes não percebiam o objetivo da atividade. A análise da duração revelou que a tônica de ADJ é sempre mais longa do que a de N na mesma posição, com diferenças significativas tanto na primeira quanto na segunda posição $(t(32)=4,220 ; p=<0.0001$, e $t(30)=2,383 ; p<0.03$, respectivamente).

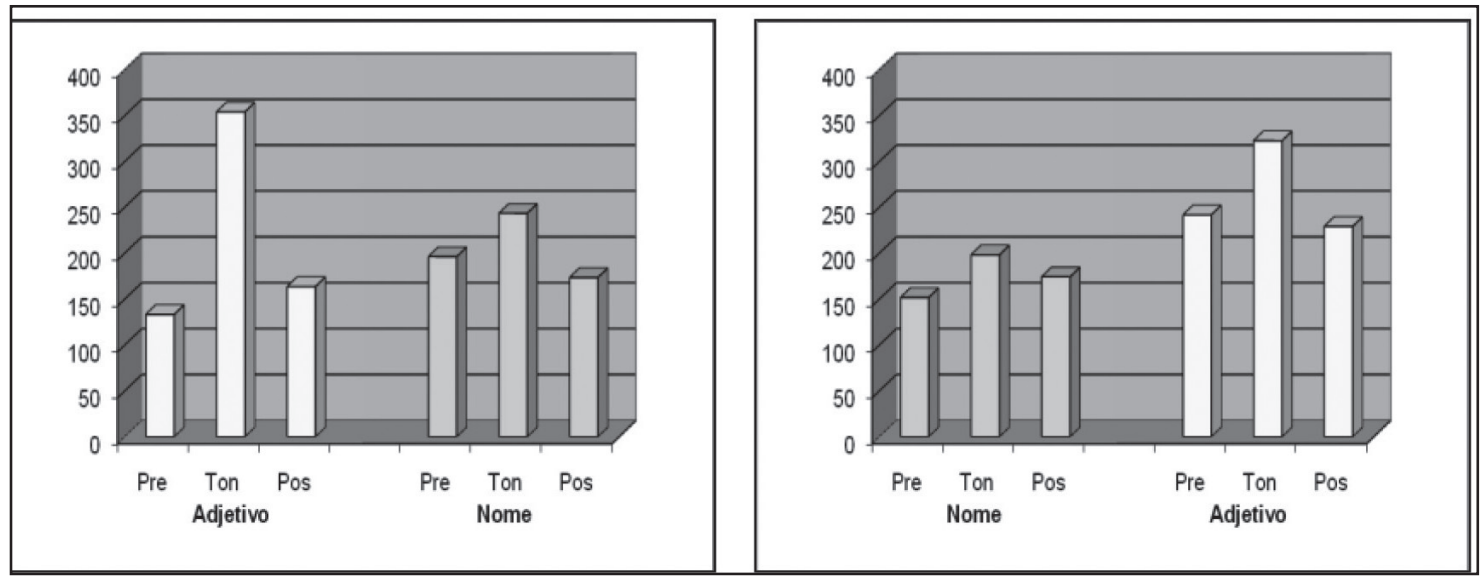

Fig. 1. Curva de duração do DP pleno (ms)

No que se refere à intensidade, as curvas de N e ADJ também apresentam comportamentos distintos. Quando se encontra em primeira posição no DP, ADJ é evidenciado com uma elevação 
da intensidade na tônica, o que não ocorre em $\mathrm{N}$ nessa posição, mesmo sendo todos os itens paroxítonos (Fig. 2).

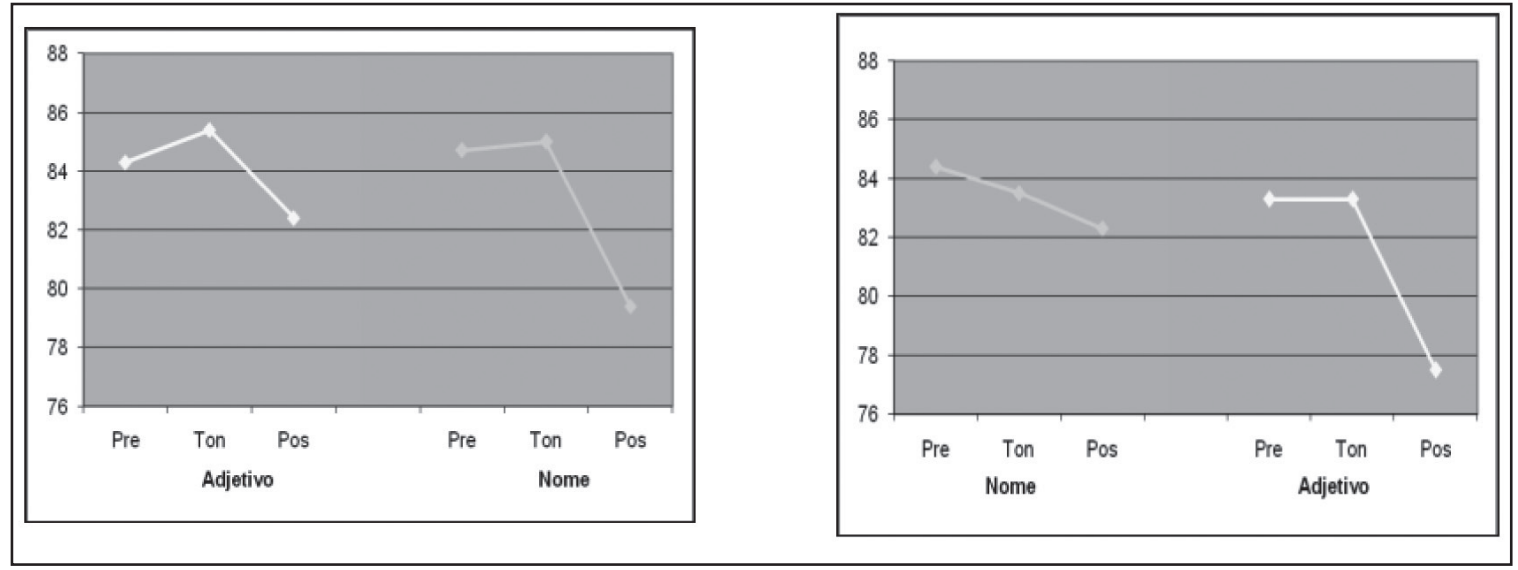

Fig. 2. Curva de Intensidade do DP pleno em situação espontânea $(d B)$

A análise do pitch também apontou para um realce de ADJ no DP: em anteposição, o adjetivo é claramente evidenciado na FDC. Comparados às analises de fala de adulto no PB (Serra, 2005), os dados da FDC se mostram ampliados, com um realce acústico do adjetivo em anteposição.

A posição estrutural dos nomes e adjetivos no DP parece, portanto, ter implicações na estrutura prosódica da FDC, o que poderia ser usado pela criança para a identificação da estrutura sintática. Em breve, avaliaremos a sensibilidade do bebê a essas variações do contorno prosódico no DP; nossa previsão é que são variações robustas o suficiente para permitir a discriminação entre DPs com adjetivo posposto e anteposto. No momento, temos resultados parciais do uso de pistas prosódicas na identificação da posição de ADJ no DP por adultos brasileiros.

\section{Identificação da ordem dos constituintes no DP por adultos a partir de pistas prosódicas}

Se propriedades acústicas do enunciado linguístico são passíveis de serem captadas por adultos tanto quanto por bebês, os diferentes contornos prosódicos do DP pleno deveriam permitir ao falante/ouvinte adulto brasileiro identificar a posição do adjetivo no sintagma. Para investigar tais habilidades, apresentamos a dez participantes adultos imagens retratando cenas de mães interagindo com suas crianças na tela de um laptop, simultaneamente a frases acusticamente manipuladas. A manipulação dos DPs, feita através do Praat (BOWERSMA \& WEENINK, 2001), buscou eliminar a informação segmental, preservando a informação prosódica. Para cada imagem teste foi elaborada uma frase contendo um DP pleno do tipo DET-N-ADJ/ADJ-N, sendo que os adjetivos escolhidos podiam ocupar a posição anteposta ou posposta a N (p.ex., bonita historia / historia bonita). Distratoras foram 
igualmente camufladas, mas sem utilização de DPs. No total, cada participante viu onze imagens (uma de treinamento, quatro testes e seis distratoras). Em uma folha, as palavras camufladas no áudio eram apresentadas desordenadamente e o participante, após ouvir a frase, deveria anotar a ordem percebida das palavras.

No total, $75 \%$ das respostas foram congruentes com o contorno prosódico apresentado na condição N-ADJ e 70\% na condição ADJ-N. Assim, apesar da força da ordem canônica N-ADJ no $\mathrm{PB}$, os participantes escolheram preferencialmente a ordem inversa na condição ADJ-N, sugerindo que o envelope prosódico do DP sinalizou a posição do adjetivo, já que não havia outra informação disponível. Ainda que parciais, os resultados apontam para uma sensibilidade do adulto falante do PB às propriedades prosódicas do DP complexo no que se refere à posição do adjetivo.

Vimos, até o momento, que diferentes configurações sintáticas do DP têm repercussões na sua estrutura prosódica, e que adultos são capazes de reconhecer tais configurações a partir da prosódia. Buscamos, ainda, verificar se, no percurso de aquisição de vocabulário, a criança faz uso de informação prosódica para identificar novos adjetivos e se relaciona o realce prosódico às implicações semântico-pragmáticas do adjetivo anteposto.

\section{O uso de pistas prosódicas na aquisição lexical}

O reconhecimento de novos adjetivos por crianças pequenas parece se apoiar no Nome. Mintz e Gleitman (2004) testaram crianças americanas de dois e três anos apresentando-lhes objetos conhecidos (carro, flor etc.) com texturas insólitas que foram nomeadas por pseudoadjetivos. Os objetos podiam ser apresentados pelos seus nomes conhecidos ou por nomes vagos (think), sempre acompanhados dos novos adjetivos (stoof). Em seguida, novos objetos eram apresentados mostrando a mesma textura que os anteriores ou não, e pedia-se à criança para apontar aquele que fosse stoof. Crianças de ambas as idades não tiveram problema em mapear o novo adjetivo à propriedade quando este foi apresentado junto ao nome do objeto (a stoof car), mas tiveram dificuldade quando acompanhado de nome vago (a stoof think). Azevedo (2008; AZEVEDO \& NAME, 2008) replicou o experimento com crianças brasileiras e obteve os mesmos resultados. Em seguida, reformulou a atividade, adicionando um sufixo aos adjetivos (maposa, bivado). Crianças de dois e três anos facilmente relacionaram o novo adjetivo à textura, apontando para o alvo congruente à familiarização. Tais resultados sugerem que informação morfofonológica auxilia a aquisição de novos adjetivos por crianças a partir de dois anos, mesmo na ausência do nome conhecido.

E quanto à informação prosodica? Matsuoka e Name (2011) partiram dos resultados de Azevedo (2008) e fizeram um piloto com oito crianças da mesma faixa etária adquirindo o PB. 
A intenção é investigar se o adjetivo prosodicamente realçado facilitaria seu mapeamento à propriedade desconhecida, mesmo na condição de apresentação do objeto por nome vago. Foram três as condições: (1) nome concreto (carro) associado a adjetivo sem realce prosódico (betujo); (2) nome vago (negócio) associado a adjetivo sem realce prosódico (betujo); e (3) nome vago (negócio) associado a adjetivo com realce prosódico (BETUJO). Diferentes objetos, texturas, nomes e pseudoadjetivos foram usados, controlando-se o gênero do nome.

Quando realçado prosodicamente, as crianças identificaram sem dificuldade o novo adjetivo, mesmo diante de nome vago. $\mathrm{Na}$ ausência de marcação prosódica, a taxa de acerto (i.e., de reconhecimento do adjetivo) foi menor, fosse na presença de nome concreto ou vago. Dado o número limitado de crianças, não é possível fazer uma análise estatística, mas é nítida a diferença da taxa de acertos entre a condição 3 - adjetivo com realce prosódico - e as demais, como podemos ver no quadro a seguir.

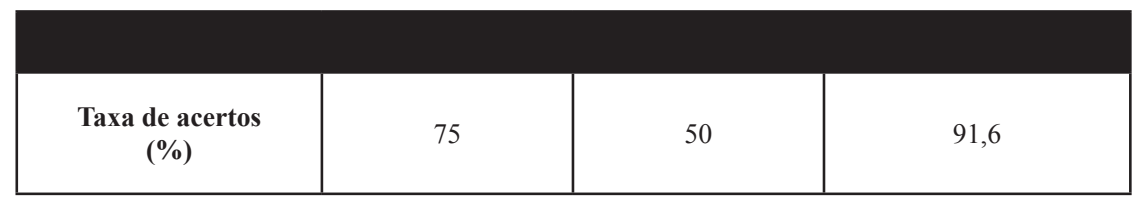

Fig. 3: Taxa de mapeamento consistente de pseudoadjetivo à propriedade (\%)

A ênfase prosódica do adjetivo parece ter facilitado seu mapeamento à nova propriedade, neutralizando a dificuldade encontrada pelas crianças diante do nome vago. Esses resultados parciais apontam, portanto, para o uso de informação prosódica pela criança no processo de aquisição lexical, para a identificação de novas palavras como pertencentes à categoria ADJ e seu mapeamento à informação semântica de propriedade de objeto.

A etapa seguinte de nossa pesquisa foi avaliar se crianças já adiantadas no processo de aquisição de vocabulário atribuem algum valor semântico à relação entre realce prosódico e posição do adjetivo no DP. Uma análise meramente acústica do enunciado permitiria identificar diferentes categorias lexicais no DP. Vimos que o adjetivo é sempre prosodicamente mais marcado do que o nome, independentemente de sua posição. Assim sendo, a criança pode generalizar, assumindo que o elemento prosodicamente realçado será sempre um adjetivo, sendo sua posição no sintagma flutuante. Porém, o realce prosódico do adjetivo anteposto advém, justamente, da carga semântico-pragmática que ele carrega com seu deslocamento, podendo acarretar alteração de sentido (homem pobre / pobre homem) ou sublinhar a intenção avaliativa do falante, e não se adequa a todos os adjetivos, mas àqueles considerados subjetivos ou qualificadores (NEVES, 2000). Até que ponto a criança adquirindo o PB é capaz de perceber tais nuances? 
Lanini (em prep.) buscou avaliar o conhecimento de crianças brasileiras, no que se refere à relação prosódia-sintaxe-semântica. Mais especificamente, investigou se crianças de seis anos relacionam o realce prosódico do adjetivo anteposto com o tipo de informação veiculada - qualificadora, subjetiva ou classificadora, objetiva.

Em uma variante da tarefa de julgamento de gramaticalidade, as crianças deveriam ajudar um boneco extraterrestre que estava aprendendo o PB, corrigindo-o quando necessário. Diante de imagens conhecidas, o ET produzia frases contendo adjetivos antepostos a nomes, variando na sua natureza (qualificador ou classificador) e no realce prosódico (presente ou ausente). Em meio a frases distratoras, foram produzidos enunciados das condições (a) adjetivo congruente à posição, prosodicamente marcado (Con +P: que LINDO carro); (b) adjetivo congruente, prosodicamente não-marcado (Con -P: que lindo carro); (c) adjetivo incongruente, prosodicamente marcado (Inc +P: que SUJO carro); (d) adjetivo incongruente, prosodicamente não-marcado (Inc -P: que sujo carro). Participaram onze crianças com idade media de seis anos. Se as crianças nessa idade já têm domínio do valor intencional do realce prosódico dado pelo falante no adjetivo anteposto, prevê-se maior aceitação da fala do ET na condição (a), que apresenta adjetivo subjetivo realçado, assim como maior rejeição na condição (c), cujo adjetivo prosodicamente marcado é de natureza objetiva, não avaliativa. Nas condições de prosódia não marcada ((b) e (d)), estimam-se taxas baixas de correção, maiores que a condição (a) e menores que a condição (c).

Como esperado, a taxa de correção para a condição Con $+\mathrm{P}$ (condição (a)) foi muito baixa, inferior a 10\% do total de enunciados. A condição (c), Inc $+\mathrm{P}$, recebeu maior taxa de correção (54,5\%), ao passo que as condições com prosódia não realçada tiveram taxas menores que (c) e maiores que (a), conforme previsto (ambas 31,8\%). Comparando-se o tipo de adjetivo com prosódia realçada ((a) vs. (c)), a diferença entre as medias foi estatisticamente significativa $(\mathrm{t}(10)=3.61, \mathrm{p}=.005)$, o mesmo se dando entre adjetivos incongruentes realçados ou não ((c) vs. (d): $t(10)=2.25$, $p<.05)$.

Os adjetivos inadequadamente antepostos (classificadores), sem realce prosódico, tiveram baixo índice de rejeição (condição (d), 31,8\%), mas quando realçados prosodicamente, foram mais rejeitados (condição (c), 54,5\%). A ênfase prosódica parece realçar a natureza semântica do adjetivo, licenciando qualificadores (condição (a), 9,1\%), mas rejeitando classificadores nessa posição (condição (c). De acordo com tais resultados, podemos concluir que crianças brasileiras, aos seis anos, dominam a relação que se estabelece entre prosódia, sintaxe e semântica, no que se refere ao adjetivo no DP. 


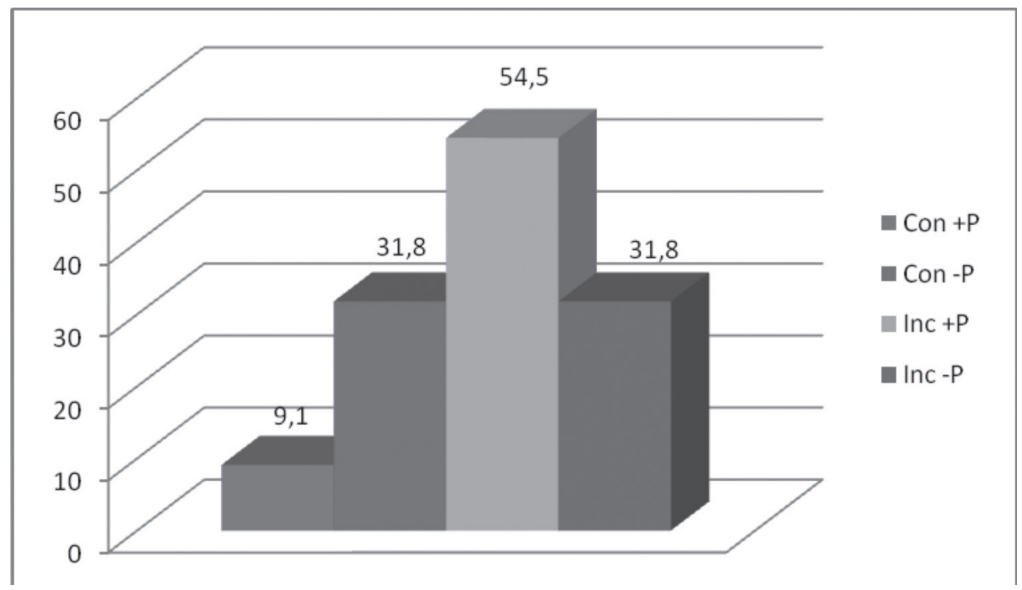

Fig. 4: Taxa de correção da fala (\%)

\section{Conclusão}

Neste artigo, investigamos o impacto da prosódia na aquisição lexical por crianças adquirindo o PB, focalizando elementos da categoria lexical ADJ. Os resultados apresentados apontam para a exploração das pistas oferecidas pelo envelope prosódico tanto por crianças como por falantes adultos. No experimento com adultos, verificamos que a informação prosódica se sobrepôs ao viés da ordem canônica, de modo que os DPs do tipo ADJ-N tiveram taxa de acerto próxima à dos DPs N-ADJ. Esses resultados são inéditos e, ainda que parciais, apontam para o uso do contorno prosódico do DP na identificação da posição dos elementos $\mathrm{N}$ e ADJ, que pode variar. Nos experimentos com crianças, verificamos que o uso da ênfase prosódica no ADJ facilitou a identificação da nova palavra como adjetivo, mesmo na ausência de marca morfofonológica e diante de nome vago. Ainda, o realce prosódico salientou a natureza semântica do adjetivo anteposto, licenciando qualificadores mas rejeitando classificadores nessa posição. Mais uma vez, trata-se de evidência de que propriedades prosódicas presentes na FDC podem auxiliar a criança no processo de constituição do léxico, sinalizando informação categorial e semântico-pragmática através do realce prosódico.

Defendemos assim que (i) essas pistas prosódicas são robustas no que tange à distinção da posição do adjetivo dentro do DP e permitem a distinção das categorias lexicais N e ADJ na FDC brasileira; (ii) crianças e adultos podem fazer uso dessas pistas no processo de aquisição lexical (e sintática) e no processamento linguístico.

Os resultados apresentados vão ao encontro de um modelo de aquisição da linguagem e de processamento adulto que considera relevante informação de natureza prosódica (cf. Bootstrapping Fonológico), assim como um modelo mais afinado com a teoria gerativa (cf. Modelo Integrado da Competência Linguística, 
MICL). O primeiro (Morgan e Demuth, 1996; Christophe et al., 1997) pressupõe que o ouvinte capta os enunciados linguísticos organizados a partir de suas propriedades prosódicas, e busca dar conta tanto do processo de aquisição de uma língua por bebês, quanto do processamento adulto. Quanto ao MICL (Corrêa e Augusto, 2007), a árvore sintática vai se formando enquanto o processamento está em curso, e o falante atribui à estrutura sintática o envelope prosódico compatível, enquanto que o ouvinte, a partir da prosódia, vai derivando sintaticamente uma dada estrutura arbórea.

\begin{abstract}
We discuss the role of prosodic information on lexical acquisition by Brazilian children, focusing on nouns and adjectives. We assume that fluent speech is organized in prosodic constituents hierarchically arranged, partially sensitive to the syntactic structure. Based on experimental results, we claim that children and adults use prosodic cues to identify the adjective order in a DP ((Experiment 1), recognize non-words as new adjectives (Experiment 2) and relate the prosodic emphasis of the pronominal adjective to its subjective value (Experiment 3). We discuss these results in light of language acquisition models.
\end{abstract}

Keywords: lexical acquisition, prosody, adjectives, phonological bootstrapping, DP

\title{
REFERÊNCIAS
}

AZEVEDO, L.O.F O papel da informação morfossintática no processo de aquisição lexical. Dissertação de Mestrado. UFJF, 2008.

AZEVEDO, L.O.F.; NAME, M.C. Uma bola maposa: o papel da nomeação na identificação de novos adjetivos. Veredas On line Número Temático com seleção dos trabalhos apresentados no GT de Psicolingüística no XXII Encontro Nacional da ANPOLL. (Goiânia, 2008), 140-143, 2008. http://www.revistaveredas.ufjf.br/ veredas psicolinguistica.html

BOWERSMA, P. \& WEENINK, D. PRAAT: a system for doing phonetics by computer. Glot International 5(9/10), p. 341-345, 2001. CHRISTOPHE, A.; GOUT, A., PEPERKAMP, S. \& MOGAN, J. Discovering words in the continuous speech stream: the role of prosody. Journal of Phonetics, 32, p. 585-598, 2003.

CHRISTOPHE, A.; GUASTI, T.; NESPOR, M.; DUPOUX, E.; VAN OOYEN, B. Reflections on phonological bootstrapping: its role for lexical and syntactic acquisition. Language and Cognitive Processes, 12 , no 5/6, p.585-612, 1997. 
CORREAA, L.M.S. ; AUGUSTO, M.R.A. Computação linguística no processamento on-line: soluções formais para a incorporação de uma derivação minimalista em modelos de processamento. Cadernos de Estudos Linguísticos, 49, p. 167-183, 2007.

FRIEDERICI, A.; THIERRY, G. (eds.) Early Language Development. Bridging Brain and Behavior. John Benjamins, 2008.

HÖHLE, B.; WEISSENBORN, J. German-learning infants' ability to detect unstressed closed-class elements in continuous speech. Developmental Science, 6, p. 122-127, 2003.

HOUSTON, D.M.; JUSCZYK, P.W.; KUIJPERS, C.; COOLEN, R.; CUTLER, A. Cross-language word segmentation by 9-month-olds. Psychonomics Bulletin Review, 7, p. 504-509, 2000.

JUSCZYK, P.W.; ASLIN, R.N. Infants' detection of the sound patterns of words in fluent speech. Cognitive Psychology, 29, p. 1-23, 1995.

JUSCZYK,P.W.; CUTLER, A.; REDANZ, N. Preference for the predominant stress patterns of English words. Child Development, 64, p. 675-687, 1993.

LANINI, A.G. O uso do adjetivo por crianças no PB: a relação entre estrutura prosódica e a anteposição. Dissertação de Mestrado. UFJF. Em prep.

MATSUOKA, A.; NAME, M.C. O uso de pistas prosódicas na identificação do adjetivo por crianças e adultos falantes do PB. Anais do VII Congresso Internacional da ABRALIN, Curitiba, p. 577-587, 2011. MINTZ, T; GLEITMAN, L. Adjectives really do modify nouns: the incremental and restricted nature of early adjective acquisition. Cognition, 84 (3), p. 267-293, 2002.

MORGAN, J. L.; DEMUTH, K. Signal to Syntax: an overview. In: J. L. MORGAN \& K. DEMUTH (Orgs.) Signal to Syntax: Bootstrapping from speech to grammar in early acquisition). Mahwah, New Jersey: Lawrence Erlbaum Associates, p. 1-22, 1996.

NAZZI, T.; IAKIMOVA, G.; BERTONCINI, J.; FRÉDONIE, S.; ALCANTARA, C. Early segmentation of fluent speech by infants acquiring French: emerging evidence for crosslinguistic differences. Journal of Memory and Language, 54, p. 283-299, 2006.

NESPOR, M.; VOGEL, I. Prosodic phonology. Dordrecht: Foris Publications, 1986.

NEVES, M. H. M. Gramática de Usos do Português. UNESP: 2000. SELKIRK, E.O. Phonology and syntax:The relation between sound and structure. Cambridge: MIT Press., 1984.

SERRA, C. R. A ordem dos adjetivos no percurso histórico: variação e prosódia. Dissertação de Mestrado. UFRJ, 2005..

SNEDEKER, J.; GLEITMAN, L. Why it is hard to label our concepts. In: HALL, G. \& S. WAXMAN (eds.) Weaving a lexicon. Bradford Books, p. 257-294, 2004. 
TURK, A.E.; JUSCZYK, P.W.; GERKEN, L.A. Do English learning infants use syllable weight to determine stress? Language and Speech, 38, p. 143-158, 1995.

WAXMAN, S. Everything had a name, and each name gave birth to a new thought: links between early word learning and conceptual organization. In: HALL, G. \& S. WAXMAN (eds.) Weaving a lexicon. Bradford Books, p. 295-335, 2004. 